\title{
INADEQUAÇÕES DO SISTEMA CONEP ÀS PESQUISAS QUALITATIVAS
}

\author{
INADEQUACY OF THE CONEP SYSTEM FOR QUALITATIVE RESEARCH
}

\author{
Stella Regina Taquette ${ }^{1}$
}

\begin{abstract}
Resumo: As normas éticas que regulam as pesquisas científicas no Brasil foram desenvolvidas na lógica biomédica, inadequada para pesquisas das ciências humanas e/ou de natureza qualitativa. Apesar dos avanços conquistados com as revisões feitas na resolução 466/12 que deram origem à resolução complementar 510/16 sobre as normas aplicáveis a pesquisas em Ciêncais Humanas e Sociais, ainda podese perceber exigências impróprias às investigações de cunho qualitativo na Plataforma Brasil e também no processo de avaliação realizado pelos integrantes dos Comitês de Ética em Pesquisa (CEPs). O presente artigo tem por objetivo descrever alguns obstáculos e conflitos éticos que podem surgir nesse processo e contribuir para o aperfeiçoamento da avaliação ética de pesquisas qualitativas. Foi realizada análise do passo a passo da submissão de projetos na Plataforma Brasil e revisão bibliográfica de estudos que enfocam conflitos éticos relacionados à apreciação de projetos pelos CEPs.
\end{abstract}

Palavras-chave: Pesquisa Qualitativa; Comitês de Ética em Pesquisa; Consentimento Livre e Esclarecido; Amostragem.

\begin{abstract}
The ethical norms that regulate scientific research in Brazil were developed in a biomedical logic, inadequate for research in the human sciences and/or of a qualitative nature. Despite the advances achieved with the revisions made in resolution 466/12 that gave rise to the complementary resolution 510/16 about the standards applicable to research in Human and Social Sciences, it is still possible to notice inappropriate requirements for qualitative investigations in Plataforma Brasil and also in the evaluation process carried out by Research Ethics Committees (RECs). This article aims to describe some ethical obstacles and conflicts that may arise in this process and contribute to the improvement of the ethical review of qualitative research. A step-by-step analysis of the submission of projects in Plataforma Brasil was carried out, as well as a bibliographic review of studies that focus on ethical conflicts related to the evaluation of projects by RECs.
\end{abstract}

Keywords: Qualitative research; Ethics Committees, Research; Informed Consent; Sampling Studies.

\section{1 Ética em pesquisa e sua normatização}

No decorrer do século XX, período de grande desenvolvimento técnico científico, ficou evidente a necessidade de proteger os sujeitos submetidos a experiências científicas principalmente após as atrocidades cometidas pelos nazistas com indivíduos vulneráveis nos campos de concentração durante a Segunda Guerra Mundial. A argumentação de que não se poderia fazer experimentos com seres humanos que os prejudicassem ou que não lhe trouxessem benefícios deu origem às normas éticas que a comunidade científica hoje utiliza para regular as pesquisas que envolvem seres humanos (VIEIRA; HOSSNE,

\footnotetext{
${ }^{1}$ Doutorado em Saúde da Criança e do Adolescente pela Universidade de São Paulo (USP). Professora Titular da Faculdade de Ciências Médicas da Universidade do Estado do Rio de Janeiro (UERJ), Rio de Janeiro, RJ, Brasil. E-mail: stella.taquette@gmail.com
} 
1998). Pode-se considerar que a normativa que inaugura a regulamentação da ética em pesquisa foi fruto do julgamento dos criminosos de guerra ocorrido na cidade de Nuremberg na Alemanha. O denominado Código de Nuremberg foi o primeiro conjunto de normas visando a ética em pesquisa científica ${ }^{2}$ (NUREMBERG CODE, 1949). Posteriormente, essa normativa foi aperfeiçoada para atendimento de novas demandas éticas das pesquisas científicas.

No período pós-guerra, infelizmente, muitos estudos antiéticos que violavam direitos humanos continuaram acontecendo. Alguns pesquisadores consideravam que o código de Nuremberg só teria utilidade em sociedades antidemocráticas, pois nas democracias, transgressões éticas como as que ocorreram durante o regime nazista seriam impossíveis de acontecer. No entanto, nos anos seguintes à divulgação do código, exemplos de experiências científicas antiéticas não faltaram, como a realizada com a população afro-americana de Tuskegee-EUA sobre a evolução natural da sífilis sem tratamento mesmo após a descoberta da penicilina, ou a inoculação do vírus da hepatite em crianças com retardo mental e a injeção de células cancerígenas em pacientes gravemente enfermos hospitalizados, ambas nos EUA, entre outras (KOTTOW, 2008). Diante desses fatos, diversas iniciativas para o respeito à ética em pesquisa e à dignidade e liberdade dos participantes de pesquisa se sucederam, como a oitava assembleia da Associação Médica Mundial realizada em 1964 em Helsinque na Finlândia, cujo tema principal foi "ética em pesquisa". Desta assembleia originou-se o principal documento norteador das pesquisas científicas, denominado de "Declaração de Helsinque", que vem sendo revisada periodicamente para acompanhar as mudanças no mundo científico (WORLD MEDICAL ASSOCIATION, 1997).

O aperfeiçoamento das normas éticas de pesquisa ao longo do tempo tem se mostrado necessário para garantir a proteção do indivíduo pesquisado, sua integridade, liberdade e dignidade, e prevenir qualquer dano que por ventura possa sofrer ao participar de um estudo científico. A Declaração de Helsinque promoveu um avanço na ética em pesquisa ao assinalar em sua introdução que o bem-estar dos participantes deve prevalecer sobre os interesses da ciência e da sociedade. Neste sentido, vale ressaltar que os princípios éticos para pesquisa vão além do que se considera como ética profissional. Espera-se que um pesquisador ético saiba distinguir atuações corretas das incorretas,

\footnotetext{
${ }^{2}$ NUREMBERG CODE. Trials of war criminal before the Nuremberg military tribunals. Control Council Law, 10:181-182, 1949. Disponível em: https://www.loc.gov/rr/frd/Military_Law/pdf/NT_warcriminals_Vol-II.pdf
} 
como, por exemplo, ter o compromisso de não adulterar nenhuma das etapas da pesquisa, não manipular resultados nem sua publicação, não plagiar trabalhos de outros pesquisadores, não se apropriar de bens materiais ou intelectuais, entre outros. Esses aspectos dizem respeito à ética e probidade do trabalho científico e à confiabilidade dos resultados produzidos, mas não necessariamente à ética em relação à integridade e bemestar dos investigados. O pesquisador pode ser ético no sentido da ética profissional e não necessariamente em relação ao pesquisado, quando, por exemplo, conduz uma pesquisa que vai beneficiar um coletivo de pessoas, mas prejudica aquele que está sendo pesquisado (KOTTOW, 2008).

Em 1978, o Relatório Belmont ${ }^{3}$, resultado do trabalho de quatro anos de uma Comissão Nacional para Proteção de Sujeitos Humanos nas Pesquisas nos EUA, deu grande impulso na regulação da ética em investigações científicas. Esta comissão foi criada após várias denúncias de estudos antiéticos desenvolvidos com seres humanos. $\mathrm{O}$ relatório estabelece três princípios éticos fundamentais como diretrizes norteadoras para a prática de pesquisa: respeito pelas pessoas, ou seja, nenhuma pesquisa pode ser feita à revelia do sujeito pesquisado, o que foi concretizado no processo de elaboração e obtenção do termo de consentimento informado para realização da pesquisa; beneficência, que significa que o benefício ao pesquisado está acima do interesse da pesquisa, estando em primeiro lugar a garantia do bem-estar do participante em detrimento de danos que possam acontecer; e justiça, de forma que todos os interessados possam participar de protocolos que tragam benefícios diretos aos mesmos com os resultados.

Contudo, apesar desses avanços, pesquisas antiéticas continuaram a ser realizadas, assim como manifestações de pessoas a favor delas. Vide os ensaios clínicos feitos com populações vulneráveis em países sem serviços de saúde adequados, e a utilização dos resultados em outros países, mais desenvolvidos, sem benefícios para as pessoas participantes das pesquisas (DINIZ; CORRÊA, 2001; SCHEFFER, 2000). Ademais, recentemente, em plena pandemia de COVID 19, a apresentadora Xuxa Meneguel, artista de grande popularidade no Brasil, vegana e defensora dos animais, fez declaração pública a favor do uso de indivíduos encarcerados em ensaios clínicos de drogas e vacinas contra a COVID 19. Ela afirmou que "já que vai ter que morrer na cadeia, que pelo menos sirva

3 The Belmont Report. In: https://www.hhs.gov/ohrp/sites/default/files/the-belmont-report508c_FINAL.pdf 
para ajudar alguma coisa"4 . Houve grave repercussão negativa por parte da sociedade civil a essa infeliz declaração, sendo a artista até denonominada por alguns de "Xuxa Mengele", comparando-a ao notório médico nazista que desenvolveu experiências torturantes com os presos políticos durante a Segunda Grande Guerra.

$\mathrm{O}$ atendimento aos códigos e normas é essencial para garantir a liberdade e dignidade do sujeito de pesquisa, porém, não é suficiente, pois imprevistos podem acontecer e outras medidas têm de ser tomadas durante o desenvolvimento da investigação diante do inesperado que se apresenta no campo (ZALUAR, 2012; MINAYO; GUERRIERO, 2014). Além disso, a integridade ética da pesquisa é indissociável de sua qualidade científica. Se falta a ética, não há qualidade nos dados e vice-versa (GUERRIERO, 2008). Um estudo para ser considerado ético deve ter justificativa clara e relevante. As questões éticas estão presentes em todo seu percurso, desde a escolha do objeto, suas bases teóricas, objetivos, percurso metodológico, interpretação e divulgação de resultados, seja aos pesquisados, à comunidade científica, aos gestores ou à sociedade como um todo (SCHMIDT, 2008; WEBSTER; LEWIS; BROWN, 2014).

\section{2 Ética em pesquisa no Brasil}

A regulamentação ética em pesquisa no Brasil ocorreu com a aprovação da Resolução no 196/96 pelo Conselho Nacional de Saúde em 1996 que prevê a criação da Comissão Nacional de Ética em Pesquisa - CONEP e dos Comitês de Ética em Pesquisa - CEP (BRASIL, 1996). Esta resolução dispõe de normas específicas referentes à ética na pesquisa envolvendo seres humanos e foi elaborada por um Grupo de Trabalho multidisciplinar e pluralista composto por pessoas de áreas de atuação diversas como médicos, enfermeiros, teólogos, farmacêuticos, odontólogos e representantes dos usuários do Sistema de Saúde (HOSSNE, 2003).

A estrutura da Resolução no 196/96 tem como base pesquisas biomédicas, de natureza quantitativa, na lógica positivista que rege a ciência no Brasil. Devido a isso, sofreu muitas críticas por parte de pesquisadores das áreas das ciências humanas e sociais (CHS) e outras que empregam métodos de natureza qualitativa em suas pesquisas. Nestas áreas, há diversas correntes de pensamento, diferente da área biomédica que em geral

4 In: https://claudiacristiane.jusbrasil.com.br/noticias/1185330614/xuxa-sugere-que-presos-sirvam-decobaias-em-testes-de-remedios-e-vacinas-serviriam-para-alguma-coisa-antes-de-morrer 
segue parâmetros rígidos e controlados. Vários itens da resolução 196/96 são impróprios às pesquisas qualitativas. Segundo diversos autores, as normas éticas têm que ser adequadas ao tipo de pesquisa nas distintas áreas de conhecimento. Elas não podem ser reduzidas a somente uma forma de se pesquisar (GUERRIERO, 2008; GUERRIERO; MINAYO, 2013). Sarti (2008) considera um paradoxo as normas éticas da CONEP terem sido criadas para impedir os abusos realizados nas pesquisas com seres humanos e ao mesmo tempo estas normas são abusivas ao não considerarem as especificidades de outras áreas do conhecimento. Já Minayo (2008) argumenta que o setor saúde extrapola suas atribuições ao tentar regular ações de outros campos de investigação.

Os debates entre pesquisadores e as críticas às inadequações da Resolução 196 incentivaram sua revisão. Em 2012 foi aprovada a Resolução 466/12, em substituição à anterior. Houve aperfeiçoamento de alguns pontos, porém ainda mantendo fortemente a lógica biomédica, persistindo exigências impróprias às pesquisas em Ciências Humanas e Sociais (BRASIL, 2012). Segundo Guerriero e Minayo (2013), não houve por parte da CONEP o aproveitamento de sugestões oferecidas por pesquisadores qualitativistas ao aprimoramento desta normativa. Essas mesmas autoras salientam que a principal incongruência dessas resoluções em relação às pesquisas das ciências sociais e humanas é a forma como se vê o participante do estudo. Nas ciências naturais a investigação se dá em seres humanos e nas ciências humanas, com seres humanos. O conhecimento é construído na relação pesquisador/pesquisado. A vulnerabilidade do participante de uma pesquisa biomédica difere da vulnerabilidade das pesquisas qualitativas, pois essas últimas não envolvem procedimentos invasivos, testes de medicamentos, exames, etc. Inclusive, em algumas investigações, o pesquisador está numa situação de maior vulnerabilidade do que o pesquisado, nas quais também deveria ser protegido. Por exemplo, quando num estudo se descobrem casos graves no próprio local de trabalho do pesquisador e, se revelados, colocam em risco seu emprego ou até a sua vida. Por outro lado, há casos em que a exigência da assinatura do Termo de Consentimento Livre e Esclarecido inviabiliza a realização da pesquisa, a exemplo dos estudos que envolvem práticas ilegais, como o aborto ou o tráfico de drogas (GUERRIERO; MINAYO, 2013).

Vale lembar, contudo, que pesquisas qualitativas, mesmo não tendo intervenção direta em seres humanos não são isentas de risco, havendo casos relatados de danos psicológicos graves (KOTTOW, 2008). O risco em participar de uma pesquisa inclui a possibilidade de prejuízos à dimensão física, psíquica, moral, intelectual, social, cultural do ser humano, em qualquer etapa da pesquisa, dela decorrente e a posteriore. 
Em 07 de abril de 2016, nova Resolução (n 510/16) foi aprovada, com vistas a solucionar as inadequações das resoluções anteriores referentes às pesquisas qualitativas. Essa nova resolução foi fruto de intenso trabalho realizado por grupo de pesquisadores das CHS da CONEP, cuja composição foi ampliada incluindo representantes de associações nacionais de pesquisa e pós-graduação das áreas de CHS. Este grupo de trabalho (GT) se reuniu diversas vezes por três anos, e a minuta da nova resolução foi disponibilizada para consulta pública à sociedade civil por 45 dias. Após as contribuições recebidas, nova versão foi elaborada e o texto final foi encaminhada pelo GT à CONEP em janeiro de 2016. Sua aprovação foi confirmada em abril de 2016 com pequenos ajustes por decisão plenária (GUERRIERO, 2016).

A Resolução $n^{\circ}$ 510/16 representa um grande avanço no campo científico. Ela dispõe sobre normas específicas aplicáveis a pesquisas em CHS e outras que utilizam metodologias próprias dessas áreas e cujos procedimentos metodológicos envolvam a utilização de dados diretamente obtidos com participantes, ou de informações identificáveis, ou que possam acarretar riscos maiores do que os existentes na vida cotidiana (BRASIL, 2016). Esta resolução define pesquisa em ciências humanas e sociais como:

[...] aquelas que se voltam para o conhecimento, compreensão das condições, existência, vivência e saberes das pessoas e dos grupos, em suas relações sociais, institucionais, seus valores culturais, suas ordenações históricas e políticas, além de suas formas de subjetividade e comunicação, de forma direta ou indireta, incluindo as modalidades de pesquisa que envolvam intervenção (BRASIL, 2016, Art.2, item XVI, pg.4).

Outros países já dispõem de procedimentos éticos específicos para pesquisas das CHS e na Noruega, a normativa ética incorpora até outras áreas como as jurídicas e a teologia (GUERRIERO; MINAYO, 2019).

As mudanças mais significativas trazidas pela Resolução 510/16, segundo Guerriero e Minayo (2016) dizem respeito a quatro itens:

(1) a composição equitativa dos membros da CONEP, ou seja, deve haver equidade entre os membros das CHS e as demais áreas que a compõem de forma a garantir uma representação equilibrada das diferentes áreas na elaboração de normas e no gerenciamento do sistema CEP/CONEP;

A análise ética dos projetos de pesquisa de que trata esta Resolução só poderá ocorrer nos Comitês de Ética em Pesquisa que comportarem representação equânime de membros das Ciências Humanas e Sociais, devendo os relatores serem escolhidos dentre os membros qualificados nessa área de conhecimento (BRASIL, 2016, Art. 26, p.9). 
(2) reconhecimento de que o mérito científico do projeto submetido deve ser avaliado por instâncias competentes, ou seja, não cabe a um membro do CEP avaliar a qualidade metodológica da proposta da pesquisa e sim conservar o foco da avaliação na proteção dos sujeitos e pesquisa;

\begin{abstract}
A avaliação científica dos aspectos teóricos dos projetos submetidos a essa Resolução compete às instâncias acadêmicas específicas, tais como comissões acadêmicas de pesquisa, bancas de pós-graduação, instituições de fomento à pesquisa, dentre outros. Não cabe ao Sistema CEP/CONEP a análise do desenho metodológico em si (BRASIL, 2016. Art. 25, §1º, p. 9).
\end{abstract}

(3) discriminação entre processo e registro de consentimento que significa na prática a ampliação das formas de apontamento do consentimento do participante que pode ser por escrito, por imagem, por som, de acordo com as características da pesquisa;

O Registro do Consentimento e do Assentimento é o meio pelo qual é explicitado o consentimento livre e esclarecido do participante ou de seuresponsável legal, sob a forma escrita, sonora, imagética, ou em outras formas que atendam às características da pesquisa e dos participantes, devendo conter informações em linguagem clara e de fácil entendimento para o suficiente esclarecimento sobre a pesquisa (BRASIL, 2016, Art. 15, p.7).

(4) explicitação das pesquisas que não necessitam da apreciação do Sistema CEP/CONEP e que as etapas preliminares não serão avaliadas (ex: visitas ao local de pesquisa, converas preliminares com lideranças), mantendo a avaliação dos estudos exploratórios ou piloto, como as descritas a seguir:

Não serão registradas nem avaliadas pelo sistemaCEP/CONEP:

I-pesquisa deopinião pública com participantes não identificados; II -pesquisa que utilize informações de acesso público, nos termos da Lei n⿳0 12.527, de 18 de novembro de 2011; III -pesquisa que utilize informações de domínio público; IV - pesquisa censitária; V - pesquisa com bancos de dados, cujas informações são agregadas, sem possibilidade de identificação individual; e VI -pesquisa realizada exclusivamente com textos científicos para revisão da literatura científica; VII -pesquisa que objetiva o aprofundamento teórico de situações que emergem espontânea e contingencialmente na prática profissional, desde que não revelem dados que possam identificar o sujeito; e VIII -atividade realizada com o intuito exclusivamente de educação, ensino ou treinamento sem finalidade de pesquisa científica, de alunos de graduação, de curso técnico, ou de profissionais em especialização (BRASIL, 2016, Art. ${ }^{\circ}$, $\S$ único, p.1-2).

Todas as etapas preliminares necessárias para que o pesquisador elabore seu projeto não são alvo de avaliação do sistema CEP/CONEP. (BRASIL, 2014, Art. 24, p.9).

\title{
3 Sistema CEP/CONEP e Plataforma Brasil
}

O sistema CEP/CONEP, criado através da Resolução 196/96 é formado pela CONEP, que é a instância máxima de avaliação ética de protocolos de pesquisa envolvendo seres humanos, e pelos CEPs dispostos em todo o território brasileiro, nas 
instituições que desenvolvem pesquisas ${ }^{5}$. A CONEP teve sua constituição designada pela Resolução $246 / 97^{6}$ e tem como atribuição implementar normas e diretrizes regulamentadoras de pesquisas envolvendo seres humanos. Tem função consultiva, deliberativa, normativa e educativa. Sua composição é multi e transdiciplinar, com 13 membros titulares de ambos os sexos, sendo cinco deles pessoas destacadas no campo da ética em pesquisa e na saúde e oito personalidades com importante atuação nos campos teológico, jurídico e outros. A composição da CONEP e dos CEPs é multidisciplinar, com profissionais de saúde, juristas, pesquisadores de áreas diversas, e inclui também a participação de representante de usuários.

Os CEPs institucionais são subordinados à CONEP e responsáveis pela revisão dos protocolos de pesquisa envolvendo seres humanos. Cabe a eles o encargo primário pelas decisões sobre a ética da pesquisa a ser desenvolvida na instutição, garantindo e resguardando a integridade e os direitos dos sujeitos participantes. Os CEPs devem também desempenhar papel consultivo e educativo através da promoção de debates sobre ética e conhecimento científico. Possíveis denúncias a respeito de pesquisas antiéticas devem ser apuradas pelos CEPs.

Todos os CEPs instituicionais são subordinados à CONEP que além do papel de supervisora é a instância que examina aspectos éticos de pesquisas envolvendo seres humanos de áreas especiais de maior risco de conflitos e de consequências negativas, como a genética e reprodução humana, ensaios clínicos de novas drogas, pesquisas com população indígena, investigações conduzidas no exterior e estudos que envolvam aspectos de biossegurança. A CONEP dá assessoria ao governo sobre questões relativas à pesquisa, principalmente ao Ministério da Saúde, ao Conselho Nacional de Saúde e ao SUS e também à sociedade em geral.

A Plataforma Brasil ${ }^{7}$, sistema para submissão de projetos de pesquisa a serem avaliados pelos CEPs correspondentes, foi lançada em 15 de dezembro de 2009, após dois anos de trabalho para aperfeiçoamento do antigo Sistema Nacional de Informação sobre Ética em Pesquisa envolvendo seres humanos (SISNEP). A Plataforma Brasil tem capacidade de alcance mais amplo do que o sistema anterior e tem a vantagem de ser um

5 Conselho Nacional de Saúde. Ética em Pesquisa (CONEP). Disponível em: https://conselho.saude.gov.br/comissao/conep/atribuicoes.html

6 Conselho Nacional de Saúde. Resoluções. Disponível em: https://conselho.saude.gov.br/resolucoes/reso_97.htm http://conselho.saude.gov.br/ultimas_noticias/2009/09_dez_plataforma_brasil.htm 
órgão de controle social, pois não é vinculado ao Poder Executivo e sim ao Conselho Nacional de Saúde. Foi criada pela CONEP em parceria com algumas áreas do Ministério da Saúde como o Departamento de Ciência e Tecnologia (DECIT) e a Agência Nacional de Vigilância Sanitária (ANVISA), entre outros.

Todo projeto de investigação envolvendo seres humanos deve ser submetido à Plataforma Brasil, ser avaliado por um CEP e aprovado antes de ser realizado. Porém, como já ressaltado, a ética na pesquisa não se restringe à essa aprovação e os problemas éticos envolvidos não se esgotam aí (GUERRIERO; MINAYO, 2019). Várias decisões éticas devem ser tomadas durante o processo de pesquisa, pois no trabalho de campo frequentemente surgem questões não previstas (DINIZ, 2008). Autores argumentam que há uma distinção entre as exigências dos CEPs e a ética da pesquisa propriamente dita, pois esta última tem um significado mais abrangente, pois inclui a responsabilidade do pesquisador com o sentido social do trabalho, das relações entre pesquisador e pesquisado, das relações com os financiadores da pesquisa, dos estudantes envolvidos, dos compromissos com a comunidade científica, com a divulgação dos resultados, etc. $\mathrm{O}$ que ocorre no contexto empírico da pesquisa pode afetar e é afetado pelo pesquisador, por seu trabalho e por sua vida real (SCHMIDT, 2008; MINAYO; GUERRIERO, 2014).

As decisões éticas para além do que é exigido na avaliação do projeto pelos CEPs são especialmente frequentes nos estudos desenvolvidos com metodologias qualitativas. Nesses estudos o processo é dinâmico, há interação entre o pesquisador e os pesquisados e não se considera ser possível a imparcialidade total, pois lidam com seres humanos que têm valores, sentimentos, visões de mundo e culturas diferentes. Durante toda a pesquisa, o pesquisador deve observar a influência que tem sobre os outros e as mudanças que ambos podem sofrer, tanto positivas quanto negativas. Podem surgir relações de amizade ou mesmo amorosas entre pesquisador e pesquisado. A participação do pesquisado pode ser tão efetiva que em alguns casos é indicado dividir a autoria do estudo com o pesquisador (MINAYO; GUERRIERO, 2014).

\section{Avaliação ética de projetos de pesquisa por CEP e seus conflitos}

Os CEPs seguem códigos e normativas para avaliar as propostas de pesquisa. Eles são compostos por no mínimo sete membros, de áreas profissionais diversas, sendo um integrante obrigatoriamente representante da comunidade. Os comitês fazem reuniões mensais para deliberação das avaliações dos projetos já revisados por seus membros que 
os relatam nessas reuniões. Não há contato pessoal entre o pesquisador proponente da pesquisa e os membros dos CEPs. O resultado da avaliação pode ser de três tipos: projeto aprovado, não aprovado ou pendente. No caso de ficar pendente, o proponente deve atender às exigências relatadas pelo CEP e submetê-las na Plataforma Brasil. Caso seja não aprovado, é permitido ao pesquisador apresentar apenas um recurso ${ }^{8}$.

Mesmo com os avanços conquistados com a promulgação da Resolução no 510/16 no que diz respeito às pesquisas em $\mathrm{CHS}$, o sistema CEP/CONEP ainda impõe exigências inadequadas às propostas de pesquisa que se utilizam dos métodos qualitativos. A maior parte dos impasses na aprovação de projetos pelos CEPs se refere a projetos qualitativos. Os proponentes de pesquisas com métodos qualitativos se deparam com dificuldades como a exigências de: cálculo amostral, garantia de isenção do pesquisador, obtenção de assinatura do consentimento informado, entre outros. Na pesquisa qualitativa quase nunca se pode de antemão estipular o tamanho amostral, que geralmente ocorre quando há saturação das informações. Também não é possível se fazer um experimento isolando o sujeito de pesquisa, pois ele sempre será influenciado pelo meio e pelo pesquisador. Por outro lado, o consentimento do pesquisado é indispensável, mas não necessariamente tem que ser por escrito e não é obrigatória sempre a privacidade, pois em certas culturas isso inexiste. (MINAYO; GUERRIERO, 2014). Essa exigência do registro por escrito felizmente foi superada pela Resolução $n^{\circ}$ 510/96 com a discriminação entre processo e registro de consentimento, que passa a poder ser feito de diversas formas (BRASIL, 2016).

Na Plataforma Brasil, o pesquisador encontra obstáculos no preenchimento do formulário on line relativos às especificadades da pesquisa qualitativa. São as exigências de apresentação do tamanho da amostra, de hipóteses, de desfecho primário e secundário, típicas de estudos de natureza quantitativa. Além dessas barreiras, outras dificuldades são vivenciadas neste caminho, como apontam vários estudos sobre situações eticamente conflituosas que frequentemente surgem no processo de revisão de estudos de natureza qualitativa pelos CEPs (MCMURPHY; LEWIS; BOULOS, 2013).

Apesar da composição dos CEPs ser diversa e a resolução 510/16 trazer uma modificação neste quesito, no sentido da necessidade de haver um equilíbrio entre as áreas de CHS e as demais que a compõem, onde projetos das CHS são submetidos, a

8 Conselho Nacional de Saúde. Plataforma Brasil. Manual do Pesquisador. Disponível em: https://conselho.saude.gov.br/images/comissoes/conep/documentos/PB/MANUAL_PESQUISADOR.pdf 
supremacia no campo científico é de pesquisas quantitativas e a na ciência em geral predomina o paradigma positivista. Portanto, a maior parte dos integrantes dos CEPs advém desse campo hegemônico e terminam por não tratar de forma equitativa as propostas de pesquisa qualitativa. Propostas de pesquisas qualitativas frequentemente ainda não são aprovadas por que os membros do CEP que o avaliam desconhecem o método ou mesmo não o consideram válido cientificamente. A validade das pesquisas qualitativas é questionada por aqueles que utilizam critérios quantitativos para a evidência científica, não têm formação em ciências humanas e desconhecem métodos de pesquisa compreensivos. Por serem de natureza diferente, os métodos qualitativos têm critérios de validade e confiabilidade distintos dos quantitativos (TAQUETTE; BORGES, 2020). Por vezes, integrantes quantitavistas de CEPs fazem exigências absurdas aos pesquisadores, impossíveis de serem cumpridas e condicionam a aprovação ética do projeto ao seu atendimento. Guerriero e Minayo (2013) citam exemplo de projeto conduzido por uma psicóloga submetido ao comitê de ética que o CEP colocou o projeto em pendência. Foi condicionada a aprovação do projeto ao cumprimento da exigência de troca da coordenação do estudo por um médico.

Nesta mesma linha de atuação enviesada de membros dos CEPs que desconhecem e/ou desconsideram pesquisas qualitativas, advêm críticas de membros do CEP a aspectos teóricos e metodológicos dos projetos submetidos, sendo que o Art. 25 do Capítulo V da Resolução $n^{\circ} 510$ dispõe que a avaliação a ser feita pelo Sistema CEP/CONEP é somente dos aspectos éticos do projeto, não cabendo a ele a análise do desenho metodológico em si, como já ressaltado no item anterior (BRASIL, 2016).

A literatura internacional evidencia que as dificuldades enfrentadas por pesquisadores qualitativistas na avaliação ética de suas propostas de pesquisa não são exclusivas do sistema brasileiro. McMurphy, Lewis e Boulos no Canadá (2013) realizaram investigação com pesquisadores qualitativistas sobre o processo de submissão de projetos qualitativos nos CEPs. Os autores evidenciaram que há uma percepção de falta de adequação entre as diretrizes de revisão ética e o desenho da pesquisa qualitativa. Estes também questionam o conhecimento e a experiência dos membros dos CEPs e a relevância de seus formulários voltados para a pesquisa biomédica e inapropriados às pesquisas qualitativas. No Brasil, reitera-se que a Resolução no 510 prevê no Art. 26 do Capítulo V que a avaliação de projetos de pesquisa que adotem perspectivas teóricometodológicas das Ciências Humanas e Sociais só podem ocorrer em CEPs que 
comportem representação equânime de membros destas áreas de conhecimento, o que nem sempre é respeitado (BRASIL, 2016).

Outras áreas e sub-áreas de conhecimento além das Humanas e Sociais que se utilizam frequentemente de métodos não quantitativos também apresentam conflitos nas revisões de seus projetos nos CEPs. Dificuldades na avaliação ética de estudos com pacientes com problemas de saúde mental são relatados por diversos autores. Existe muito preconceito a respeito das doenças mentais e são poucos os membros dos CEPs que têm expertise sobre o tema. Alguns são conservadores e têm medo que a pesquisa possa causar danos aos participantes (KEOGH; DALY, 2009; GRAOR; KNAPIK,2013). A avaliação amiúde é feita com base em estereótipos e/ou conhecimentos do senso comum. Essa restrição a pesquisas com indivíduos portadores de transtornos mentais pode resultar na exclusão deste público, com perda de conhecimentos potencialmente valiosos.

Situações semelhantes podem acontecer em projetos sobre temas sensíveis, como aqueles relativos à sexualidade, aborto, violências e a preconceitos como homofobia, racismo e discriminação de gênero. Esses projetos também são repetidas vezes tratados pelos membros dos CEPs por seus próprios princípios morais e até religiosos e não por bases científicas (TAQUETTE et al., 2005). Estudos com adolescentes igualmente são motivo de questionamentos éticos, pois usualmente são julgados por pessoas que se apoiam em padrões individuais nas avaliações, desconhecendo o direito do adolescente à autonomia, previsto no Estatuto da Criança e do Adoelscente - ECA e normatizado pela Sociedade Brasileira de Pediatria (TAQUETTE; PEREIRA, 2012). Para se evitar interpretações inadequadas por parte dos membros dos comitês, seja por desconhecimento, conservadorismo ou preconceito, o pesquisador em sua proposta de pesquisa deve explicar detalhadamente sobre os aspectos éticos e como irá prevenir quebras de confidencialidade e desrespeito à autonomia quando o público-alvo é de população vulnerável ou o tema é sensível (KEOGH; DALY, 2009).

Não são incomuns os casos de pesquisadores cujos projetos a serem realizados em mais de uma instituição e por esse motivo têm de ser avaliados por mais de um CEP, serem demandados com novas exigências em cada CEP, diferentes dos anteriores. Algumas não fazem sentido à pesquisa qualitativa, como a apresentação dos cálculos matemáticos e testes estatísticos. Outros fazem exigências relacionadas ao consentimento informado (MCMURPHY; LEWIS; BOULOS, 2013).

Os conflitos relatados podem estar ocorrendo não só por insuficiente formação dos membros dos CEPs, mas também devido ao pouco diálogo existente entre o CEP e 
os pesquisadores que neles submetem seus projetos. A pouca comunicação entre proponentes e avaliadores deixa a impressão de certo autoritarismo por parte dos seus integrantes. Essa circunstância é facilitadora de conflitos. O pesquisador é totalmente desvinculado do processo de revisão, pois raramente lhe é permitido dialogar no colegiado dos CEPs. As exigências de mudanças solicitadas pelos CEPs por vezes não estão de acordo com os projetos de pesquisa e não são aceitáveis para a integridade pela mesma (MCMURPHY; LEWIS; BOULOS, 2013; MCCORMACK et al., 2012).

Os estudos relatados evidenciam o imperativo do aperfeiçoamento do processo de análise de projetos de pesquisa qualitativa. Alguns autores defendem que os CEPs deveriam desempenhar um papel mais educativo do que disciplinador e que houvesse maior comunicação entre as partes interessadas (FRANKLIN et al., 2012). A ética em pesquisa não é uma prática estática. Sua gestão deve ser compartilhada entre os integrantes do comitê e a equipe de pesquisa, com diálogo facilitado. A avaliação ética dos comitês poderia ser dinâmica e processual como o é a própria pesquisa. Precisa haver um aumento da transparência do processo de revisão e autores argumentam que este poderia ser semelhante ao de revisão por pares de textos acadêmicos (MCMURPHY; LEWIS; BOULOS, 2013). Alguns autores até questionam se os estudos em CHS devem ser avaliados por colegiados, se não seria suficiente pareceres de profissionais capacitados da área (DINIZ, 2008).

Sem desconsiderar a importância do papel dos CEPs, a permanência de inadequações no processo de revisão ética para as pesquisas qualitativas qualitativa provoca um clima de desconfiança entre o pesquisador e o CEP que prejudica o andamento das avaliações. Este procedimento pode ser aprimorado se os membros dos CEPs agirem de forma mais amigável e propuserem a participação do pesquisador, no sentido de contribuir para melhor compreensão do projeto que está sendo avaliado. É necessário que os CEPs disponham de integrantes com maior conhecimento sobre as abordagens qualitativas para que sejam capazes de avaliar não só os benefícios, mas também os danos deste tipo de pesquisa. A falta desse conhecimento por vezes impede a aprovação dos projetos de pesquisa, mas também pode negligenciar as práticas que garantem a proteção dos participantes (PETER, 2015). 


\section{Considerações finais}

O processo de avaliação ética de projetos de pesquisa que envolvem seres humanos é essencial para garantir a proteção do indivíduo pesquisado, sua integridade e dignidade. Contudo, ele não é suficiente, pois a ética na pesquisa perpassa todo o seu desenvolvimento, desde a escolha do objeto a ser pesquisado até a divulgação dos resultados. No Brasil houve grande progresso da ética em pesquisa, com fortalecimento dos mecanismos de avaliação, de forma democrática e com controle social. Contudo, não se trata de um processo acabado e sim em evolução, assim como tem ocorrido no mundo desde a pioneira Declaração de Helsinque, base das resoluções que norteiam o processo de revisão ética das pesquisas no Brasil. Dentro desse ponto de vista, vale ressaltar as dificuldades do processo avaliativo de pesquisas de natureza qualitativa ainda não foram totalmente superadas, mesmo com avanços trazidos pela Resolução $n^{\circ}$ 510/16.

Portanto, a título de conclusão, fica clara a necessidade de reformulação do processo para melhor avaliação de propostas de investigaão com métodos qualitativos, principalmente no que diz respeito a alguns itens da Plataforma Brasil, à composição dos CEPs e à relação destes com os pesquisadores. Sugere-se a criação nesta Plataforma de uma interface própria para as pesquisas de natureza qualitativa e a renovação do processo de avaliação dos CEPs com a inclusão de equitativa de membros com conhecimento neste tipo de método e a possibilidade de diálogo entre as partes para solução dos conflitos.

\section{Referências}

BRASIL. Ministério Da Saúde. Conselho Nacional De Saúde. Resolução 196/96. Disponível em: https://bvsms.saude.gov.br/bvs/saudelegis/cns/1996/res0196_10_10_1996.html. Acesso em 04 ago. 2021.

BRASIL. Ministério da Saúde. Conselho Nacional de Saúde. Resolução 466/2012. Disponível em: http://conselho.saude.gov.br/resolucoes/2012/Reso466.pdf. Acesso em 04 ago. 2021.

BRASIL. Ministério da Saúde. Conselho Nacional de Saúde. Resolução 510/2016. Disponível em: http://www.conselho.saude.gov.br/resolucoes/2016/Reso510.pdf. Acesso em 04 ago. 2021.

DINIZ, D.; CORRÊA M. Declaração de Helsinki: relativismo e vulnerabilidade. Cad. Saúde Pública, [S.I.], v.17, n.3, p.679-688, 2001.

DINIZ, D. Ética na pesquisa em ciências humanas: novos desafios. Ciência \&Saúde Coletiva, [S.I.], v.13, n. 2, p.417-426, 2008.

FRANKLIN, P. et al. Research ethics in accessing hospital staff and securing informed consent. Qual Health Res., [S.I.], v.22, n.12, p.1727-38, 2012. 
GRAOR, C.H.; KNAPIK, G.P. Addressing methodological and ethical challenges of qualitative health research on persons with schizophrenia and bipolar disorder.

Arch Psychiatr Nurs, [SI.], v. 27, n. 2, p.65-71, 2013.

GUERRIERO, I.C.Z. Síntese das reflexões da reunião sobre ética em pesquisa qualitativa em saúde, Guarujá-SP. Ciência \&Saúde Coletiva, [S.I.], v.13, n.12, p.459-463, 2008.

GUERRIERO, I.C.Z.; MINAYO, M.C.S. O desafio de revisar aspectos éticos das pesquisas em ciências sociais e humanas: a necessidade de diretrizes específicas. Physis, [S.I.], v.23, n.3, p.763-782, 2013.

MINAYO, M.C.S.; GUERRIERO, I.C.Z.;. Reflexividade como éthos da pesquisa qualitativa. Ciência \&Saúde Coletiva, [S.I.], v.19, n.4, p.1103-1112, 2014.

GUERRIERO, I.C.Z. Resolução n ${ }^{\circ} 510$ de 7 de abril de /2016 que trata das especificidades éticas das pesquisas nas ciências humanas e sociais e de outras que utilizam metodologias próprias dessas áreas. Ciência \&Saúde Coletiva, [S.I.], v.21, n.8, p.2619-2629, 2019.

GUERRIERO, I.C.Z.; MINAYO, M.C.S. A aprovação da Resolução CNS nº 510/2016 é um avanço para a ciência brasileira. Saúde Soc, [S.I.], v.28, n.4, p.299-310, 2019.

HOSSNE, W.S. The power and the injustices of research involving human beings. Interface Comunic, Saúde, Educ, [S.I.], v.7, n.12, p.55-70, 2003.

KEOGH, B.; DALY, L. The ethics of conducting research with mental health service users. Br J Nurs, [S.I.], v.18, n.5, p.277-81, 2009.

KOTTOW, M. História da ética em pesquisas com seres humanos. RECIIS- Revista Eletrônica de Comunicação Informação \& Inovação em Saúde, [S.I.], v.2, n.Sup.1, p.Sup7Sup18, 2008.

MCCORMACK, D.; CARR, T.; MCCLOSKEY, R.; KEEPING-BURKE, L.; FURLONG, K.E.; DOUCET, S.J. Getting through ethics: the fit between research ethics board assessments and qualitative research. Empir Res Hum Res Ethics, [S.I.], v.7, n.5, p.30-36, 2012.

MCMURPHY, S.; LEWIS, J.; BOULOS, P. Extending the olive branch. J Empir Res Hum Res Ethics, [S.I.], v.8, n.4, p.29-36, 2013.

MINAYO, M.C.S. Antropological contributions for thinking and acting in the health área and its ethical dilemas. Ciência \&Saúde Coletiva, [S.I.], v.13, n.2, p.329-339, 2008.

MINAYO, M.C.S.; GUERRIERO, I.C.Z. Reflexividade como éthos da pesquisa qualitativa. Ciência \&Saúde Coletiva, [S.I.], v.19, n.4, p.1103-1112, 2014.

PETER, E. The ethics in qualitative health research: special considerations. Ciência \& Saúde Coletiva, [S.I.], v.20, n.9, p.2625-2630., 2015.

SARTI, C.A. A difficult dialogue. Ciência \& Saúde Coletiva, [S.I.], v.13, n.2, p.315-317, 2008.

SCHEFFER, M. Tecnologia, aids e ética em pesquisa. Interface - Comunicação, Saúde, Educação, [S.I.], v.4, n.6, p.173-176, 2000.

SCHMIDT, M.L.S. Pesquisa participante e formação ética do pesquisador na área da saúde. Ciência \&Saúde Coletiva, [S.I.], v.13, n. 2, p.391-398, 2008. 
TAQUETTE, S.R. et al. Conflitos éticos no atendimento à saúde de adolescentes. Cad. Saúde Pública, [S.I.], v.21, n.6, p.1717-1725, 2005.

TAQUETTE, S.R.; PEREIRA, S.M. Adolescência, bioética e saúde In: TAQUETTE, S.R.; CALDAS, C.P. Ética e pesquisa com populações vulneráveis. Rio de Janeiro, Eduerj, 2012. p.147-170.

TAQUETTE, S.R.; BORGES, L. Pesquisa qualitativa para todos. Petrópolis: Vozes, 2020.

VIEIRA, S; HOSSNE, W.S. A ética e a metodologia. São Paulo: Pioneira, 1998.

WEBSTER S, LEWIS, BROWN A. Ethical considerations in qualitative research. In:

RITCHIE, J. et al. (org.). Qualitative Research Practice. Second Edition. Sage Publication. London, 2014. p.77-110.

WORLD MEDICAL ASSOCIATION. Declaration of Helsinki: Recommendation guiding physicians in biomedical research involving human subjects. JAMA, [S.I.], v. 277, n. 11, p.925926, 1997.

ZALUAR, A. Pesquisando no perigo com jovens vulneráveis: que ética? In: TAQUETTE, S.R.; CALDAS, C.P. Ética e pesquisa com populações vulneráveis. Rio de Janeiro, Eduerj, 2012. p.189-218.

Convite feito em: 10 de maio de 2021 Revisão feita em: 12 de novembro de 2021 